\title{
Sea Turtle Rehabilitation Success Increases with Body Size and Differs Among Species
}

\author{
LINDA BAKER 1,2 \\ WILL EDWARDS 1,2 \\ DAVID A. PIKE 2,3 \\ 1College of Marine and Environmental Sciences, \\ James Cook University, Cairns, Queensland, Australia \\ ${ }^{2}$ Centre for Tropical Environmental \& Sustainability Science, \\ James Cook University, Cairns, Queensland, Australia \\ 3 College of Marine and Environmental Sciences, \\ James Cook University, Townsville, Queensland, Australia
}

\begin{abstract}
Wildlife rehabilitation can contribute to species conservation by releasing healthy individuals back into the wild and educating the public about threatening processes. Rehabilitation has substantial financial costs, however, and thus it is important to understand the success rates of these potential conservation management actions. We quantified the success rates for 1700 sea turtles admitted to rehabilitation facilities in Florida (USA) between 1986 and 2004. Rehabilitation success was low: 61.5\% of turtles died in rehabilitation and only $36.8 \%$ were released back into the wild. A further $1.6 \%$ of turtles were maintained in captivity permanently due to the severe nature of their injuries. Most mortality occurred early during the rehabilitation process (within a few weeks), and successful rehabilitation often took several months to more than 3 yr. Loggerhead turtles (Caretta caretta) were most likely to survive rehabilitation, followed by Kemp's ridleys (Lepidochelys kempii) and green turtles (Chelonia mydas); for all three species, larger individuals had an increased chance of successful rehabilitation. At face value, the low rates of rehabilitated turtles successfully released back into the wild may contribute only modestly to conservation in terms of contributing to population viability. However, many rehabilitation facilities provide important educational experiences that increase public awareness of the threats facing animals and highlight potential conservation solutions. Media coverage highlighting the release of rehabilitated animals further extends the conservation value of these efforts. Wildlife rehabilitation provides important direct benefits that, combined with social benefits, together may justify the expense and difficulty of rehabilitating individual animals.
\end{abstract}

Keywords: Animal hospital, endangered species, human intervention, injury, marine turtle, public engagement, sea turtle stranding, survival, veterinary care, wildlife rehabilitation

\section{INTRODUCTION}

Wildlife rehabilitation is the process of treating injured, sick or orphaned animals and releasing them back into the wild. As conservation has moved to the forefront of ecology, releasing rehabilitated animals as a way of enhancing wildlife populations is becoming more frequent (Karesh 1995; Cardona et al 2012; Mestre et al 2014). These actions have the potential to play significant roles in stabilizing or augmenting wildlife populations, especially those in conservation peril (Karesh 1995). Rehabilitation based on sound conservation and biological principles (Tribe and Brown 2000; Ferraro and Pattanayak 2006) ensures that available resources can be allocated towards the most effective conservation measures (Tribe and Brown 2000; Ferraro and Pattanayak 2006; Wimberger et al 2010; Feck and Hamann 2013). In some cases, however, the high costs of rehabilitation or low success rates may be too great to warrant widespread implementation. Thus, understanding the success rates of rehabilitation and how they vary with species biology (e.g., body size, sex) will enhance our ability to gauge how these activities can contribute to conservation.

The primary objective behind wildlife rehabilitation is the welfare of individual animals (Moore et al 2007), which are often accepted into rehabilitation without prioritizing rare or endangered species (Karesh 1995; Tribe and Brown 2000). During catastrophic events, there may be insufficient resources to care for all affected individuals and decisions may need to be made about which animals to rehabilitate. The financial costs of rehabilitation are large (Karesh 1995; Tribe and Brown 2000; Moore et al 2007; Feck and Hamann 2013) and in some cases those resources could be more effectively directed towards conservation measures aimed at preventing wildlife injury (Moore et al 2007). This presents a conflict between public support behind rehabilitating injured wildlife as a conservation measure (reviewed by Feck and Hamann 2013) and how effective rehabilitation actually is for maintaining or increasing population size, compared to the actual costs of other conservation efforts. An added benefit of treating animals in captivity is the potential for positive educational interactions between humans and wildlife, which could contribute to conservation by garnering public support (Tribe and Brown 2000; Moore et al 2007; Cardona et al 
2012; Feck and Hamann 2013).

The efficacy of rehabilitation programs for mammals and birds has been well reviewed (Karesh 1995; Tribe and Brown 2000; Moore et al 2007), but evaluations of other fauna are limited (Dodd and Seigel 1991). Sea turtle populations are in decline globally and integrated conservation efforts are required to prevent extinction (Wallace et al 2011). Sea turtle rehabilitation is usually achieved through medical management of sick or injured animals by veterinary surgeons in wildlife hospitals (Casal and Orós 2009; Feck and Hamann 2013). The majority of animals in rehabilitation are taken there because of some previous negative interaction with humans (Tribe and Brown 2000; Feck and Hamann 2013), including entanglement in fishing gear (Allen 2000; Dutton and Squires 2008; Bagarinao 2011), being hit by a boat or propeller, and a wide range of other causes (Shaver and Teas 1999; Dutton and Squires 2008; Bagarinao 2011). Current information on the success rates of sea turtle rehabilitation is limited but suggests that the proportion of animals released back into the wild is low (Haines et al 2000; Haines and Limpus 2001; Greenland et al 2004; Greenland and Limpus 2006; 2008; Biddle and Limpus 2011). Records from Queensland, Australia
(1999 to 2010) suggest that only $26 \%$ of stranded sea turtles found washed up on beaches were successfully rehabilitated and released back into the wild (Table 1). The survival rate of rehabilitated animals once released back into the wild could be lower than that of wild turtles, further reducing overall success rates in terms of the potential for individuals to contribute to the population (Cardona et al 2012). Widespread rehabilitation of sick or injured turtles currently supplements other conservation efforts (IUCN 1995; Casal and Orós 2009; Goldberg et al 2011; Mestre et al 2014) but we still have a poor understanding of the conservation potential of rehabilitation in terms of numbers of healthy animals released (even without knowing their longer-term individual survival; Cardona et al 2012; Mestre et al 2014).

To fill this knowledge gap, we analyzed data on injured sea turtles admitted into rehabilitation facilities from 1986 to 2004 in Florida (USA) to determine the overall success rates of rehabilitation, and whether body size, sex or species identity influenced rehabilitation outcome. Understanding the outcomes of rehabilitation is essential because the public often views these as conservation efforts (Feck and Hamann 2013; Mestre et al 2014).

Table 1. Yearly data on rehabilitated sea turtles stranded along the Queensland, Australia, coast between 1999 and 2010. Data are summaries from the Queensland marine wildlife stranding and mortality database (StrandNet; compiled from Haines et al. 2000, Haines and Limpus 2001, Greenland et al. 2004, Greenland and Limpus 2006, 2008, Biddle and Limpus 2011). Raw data were unavailable for analysis.

\begin{tabular}{|c|c|c|c|c|c|c|c|}
\hline \multirow[b]{2}{*}{ Year } & \multirow[b]{2}{*}{$\begin{array}{l}\text { Died during } \\
\text { rehabilitation } \\
\text { or euthanized }\end{array}$} & \multirow[b]{2}{*}{$\begin{array}{l}\text { Successfully } \\
\text { rehabilitated } \\
\text { and released }\end{array}$} & \multirow[b]{2}{*}{$\begin{array}{c}\text { Unknown } \\
\text { rehabilitation } \\
\text { outcome }\end{array}$} & \multirow[b]{2}{*}{ Total turtles } & \multirow[b]{2}{*}{$\begin{array}{l}\text { Success rate } \\
\text { (proportion) }\end{array}$} & \multicolumn{2}{|c|}{$\begin{array}{c}\text { 95\% confidence limits } \\
\text { Lower }\end{array}$} \\
\hline & & & & & & Lower & Upper \\
\hline 1999 & 77 & 97 & 0 & 174 & 0.557 & 0.483 & 0.63 \\
\hline 2000 & 75 & 61 & 0 & 136 & 0.449 & 0.366 & 0.533 \\
\hline 2001 & 29 & 2 & 3 & 60 & 0.059 & 0.011 & 0.188 \\
\hline 2002 & 39 & 20 & 1 & 60 & 0.333 & 0.221 & 0.466 \\
\hline 2003 & 55 & 16 & 8 & 79 & 0.203 & 0.122 & 0.308 \\
\hline 2004 & 26 & 14 & 21 & 61 & 0.23 & 0.134 & 0.35 \\
\hline 2005 & 53 & 19 & 11 & 83 & 0.229 & 0.147 & 0.33 \\
\hline 2006 & 89 & 25 & 14 & 128 & 0.195 & 0.134 & 0.272 \\
\hline 2007 & 145 & 45 & 33 & 223 & 0.202 & 0.153 & 0.259 \\
\hline 2008 & 104 & 33 & 52 & 189 & 0.175 & 0.125 & 0.234 \\
\hline 2009 & 128 & 40 & 66 & 234 & 0.171 & 0.127 & 0.225 \\
\hline 2010 & 92 & 41 & 39 & 172 & 0.238 & 0.179 & 0.307 \\
\hline Total & 912 & 413 & 248 & 1573 & 0.263 & 0.241 & 0.285 \\
\hline
\end{tabular}




\section{MATERIALS AND METHODS}

Sea Turtle Stranding and Rehabilitation. We used standardized data collected by the Sea Turtle Stranding and Salvage Network (STSSN) in Florida from 1986 to 2004 (Shaver and Teas 1999; Foley et al 2005). The STSSN documents marine turtle strandings along the Gulf of Mexico and Atlantic coastlines of the United States. Information about each turtle stranding event, when known, is recorded on a form (e.g. date, location, species, sex, body size; see STSSN Stranding Report at www.sefsc.noaa.gov/ species/turtles/strandings.htm), and all live turtles are transported to rehabilitation facilities. Follow-up details entered into the dataset often included the fate of each turtle (died in captivity, euthanized, released, or maintained in captivity indefinitely) and the date of death or release back into the wild (as appropriate).

From 1986 to 2004, a total of 2,462 live-stranded sea turtles were taken into rehabilitation, representing all live stranding events recorded in Florida. The dataset did not include sufficient information about the type of injuries that potentially caused the turtle to become stranded to include this variable in the analysis. We used curved carapace length (CCL; measured upon arrival at rehabilitation) as a measure of turtle body size; when straight-line carapace length (SCL) was the only measurement available, we converted this to CCL using Teas' (1993) equation: $\mathrm{SCL}=0.294+$ $(0.937 \times \mathrm{CCL})$.

Rehabilitation Success Rates. We calculated the proportion of turtles that died in rehabilitation, were euthanized, were successfully released into the wild, and deemed to have injuries too severe for release and thus were maintained in captivity permanently. Proportional values and their $95 \%$ confidence limits were generated using the Agresti-Coull approximation (Agresti and Coull 1998).

To estimate the average amount of time a turtle spent in rehabilitation, we calculated the mean and standard deviation of the number of days spent in rehabilitation. For this analysis, we used the 1,700 turtles for which the outcome of rehabilitation (died or survived) and the number of days spent in rehabilitation were known. We used a Mann-Whitney U-test to compare the distribution of the number of days spent in rehabilitation between turtles that died versus those that survived.

\section{Impacts of Phenotype on Rehabilitation}

Outcome. We used generalized linear models (GLMs) implemented in the program $\mathrm{R}$ (version 2.15.0; R Development Core Team 2012) to estimate the influence of multiple variables on sea turtle rehabilitation success rates. The response variable, survival, is binomial and describes whether each turtle lived or died. Explanatory variables included species identity, sex, body size, and the duration of rehabilitation (number of days). Because the species we included differed in body size by orders of magnitude, we converted raw CCL measurements of turtles in our study to Z-scores to allow us to compare distributions among species (using $n=1622$ turtles for which body size data were available; Table 2). Z-scores ranged from -3 to +3 , with a value of 0 representing a turtle of average size for the species (i.e., a $Z$-score represents the standardized deviation from a mean of zero), negative values indicating smaller turtles, and positive values indicating larger turtles. This approach also allowed us to test for potential effects of individual body size on survival, such as whether larger turtles were more likely to be successfully rehabilitated.

Table 2. Summary of known variables and associated sample sizes for the standardized data on stranded sea turtles gathered by the Florida Sea Turtle Stranding and Salvage Network between 1986 and 2004.

\begin{tabular}{|c|c|c|c|c|c|c|}
\hline Species & $\begin{array}{l}\text { Total no. of } \\
\text { turtles }\end{array}$ & $\begin{array}{c}\text { Outcome } \\
\text { known }\end{array}$ & $\begin{array}{l}\text { Sex and } \\
\text { outcome } \\
\text { known }\end{array}$ & $\begin{array}{l}\text { Time and } \\
\text { outcome } \\
\text { known }\end{array}$ & $\begin{array}{l}\text { Size and } \\
\text { outcome } \\
\text { known }\end{array}$ & All variables known \\
\hline Green & 1218 & 860 & 241 & 750 & 828 & 184 \\
\hline Loggerhead & 931 & 628 & 215 & 565 & 592 & 170 \\
\hline Kemp's ridley & 186 & 123 & 29 & 108 & 113 & 20 \\
\hline Hawksbill & 113 & 76 & 10 & 72 & 76 & 9 \\
\hline Leatherback & 12 & 11 & 6 & 11 & 11 & 6 \\
\hline Olive ridley & 2 & 2 & 2 & 2 & 2 & 2 \\
\hline Total (\%) & 2462 & 1700 (69) & 503 & 1508 & 1622 & 391 (15.9) \\
\hline
\end{tabular}


For analysis of the influence of multiple variables on rehabilitation outcomes, we used the subset of records for which all data were available; common omissions included sex and the outcome of rehabilitation efforts, as well as 2 turtles that were released by vandals and another that escaped during rehabilitation (Table 2). This approach ensures that potentially competing models were refitted with the same sample size each time. Within the subset of records for which all data were available, sample sizes were too low for analysis for 3 species (hawksbill Eretmocehlys imbricata, $\mathrm{n}=9$; leatherback Dermochelys coriacea, $\mathrm{n}=6$; and olive ridley Lepidochelys olivacea, $\mathrm{n}=2$ ). This resulted in a final dataset of 374 individuals, representing green Chelonia mydas ( $\mathrm{n}=184)$, loggerhead Caretta caretta ( $\mathrm{n}$ $=170$ ), and Kemp's ridley turtles Lepidochelys kempii (n $=20$ ).

Information theoretic approaches acknowledge that a range of different models may display similar abilities to describe true data. The process thus requires fitting a range of competing models, which are then compared in terms of their explanatory abilities. Akaike's information criterion (AIC) is a measure of information lost in fitting a given model, with the lowest values indicating the best approximation of data. This approach can, however, reveal that multiple models are equally supported descriptions of the true pattern. Final model selection is thus based on the magnitude of the difference in AIC values between models. The best-supported models (i.e., $\triangle$ AICs) are those that make up the top $90 \%$ of Akaike weights and have relative deviations from the best model of less than 2 (Burnham and Anderson 1998).

We first developed a global GLM that fitted all explanatory variables: the full model. To determine which variables were required to generate the best approximating model, we used the dredge function in the R package 'MuMIn' (Barto 2012) to produce likelihood estimates for all possible nested models (models including subsets of variables in the global model) and chose the most parsimonious model (or combination of models) based on $\triangle \mathrm{AIC}$ for small sample sizes $(\triangle \mathrm{AICc})$. The response variable was logit-transformed to ensure linearity. Thus, the coefficients associated with the explanatory variables included in the model are returned as log-odds ratios. To produce intuitive results, we transformed coefficient value log-odds to simple odds ratios.

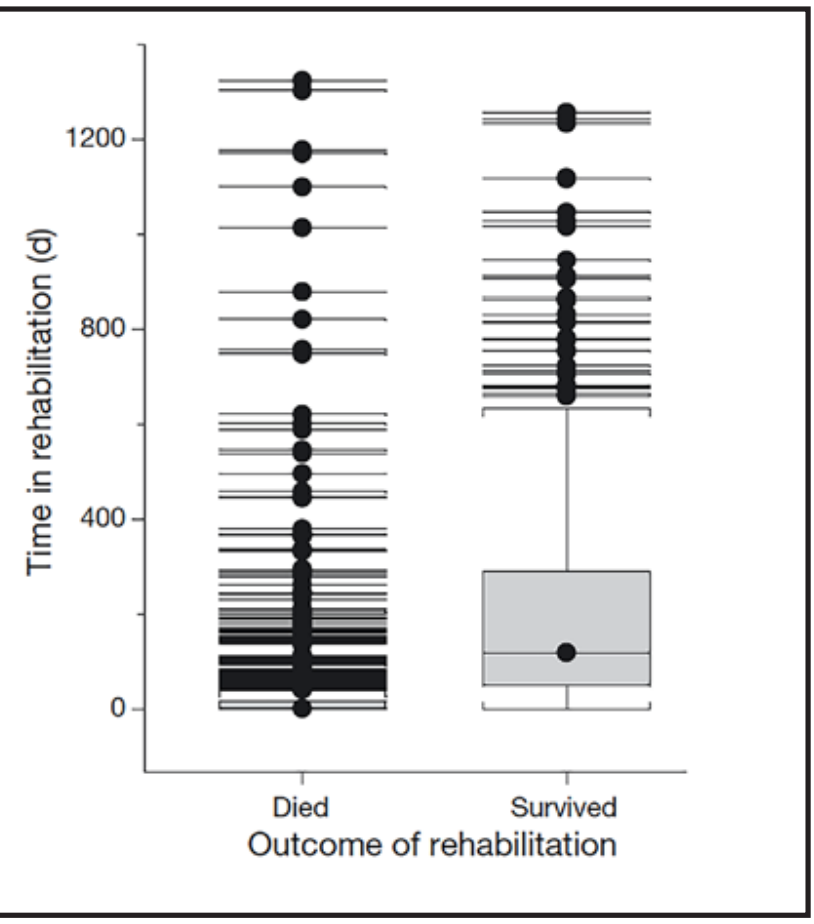

Figure 1. Number of days spent in treatment by stranded turtles that died during rehabilitation $(n=884)$ or survived $(n=624)$. All turtles were found stranded alive along the Florida coast by the Sea Turtle Stranding and Salvage Network and taken to rehabilitation facilities between 1986 and 2004. Shown are box plots (in grey) with outliers (filled circles and lines).

\section{RESULTS}

Rehabilitation Success Rate. Of the 1700 sea turtles with known rehabilitation outcomes, 626 individuals (36.8\%) survived and were subsequently released back into the wild, 1,047 individuals (55.3\%) died in rehabilitation and 27 individuals (1.6\%) survived but remained in captivity (Table 2). The mean number of days spent in rehabilitation differed between turtles that died and those that survived $(Z$ $=-24.59, \mathrm{p}<0.001)$. Turtles that were successfully rehabilitated and released back into the wild spent a greater mean time in rehabilitation than those that died (Figure 1).

\section{Impacts of Phenotype on Rehabilitation} Outcome. The most parsimonious model (GLM2) included the terms body size, time in rehabilitation and species identity (Table 3). GLM2 had a smaller AIC (139.5) compared to the global GLM (GLM1; AIC = 141.5). The difference in AIC between these two models is equal to two, and thus both are equally plausible (Burnham and Anderson 1998). We chose to focus on the model with the lowest AIC. The 14 other possible competing models did not fit our data as strongly (i.e., $\triangle \mathrm{AICc}>2$ ) (Table 4). 
Table 3. Plausible models for estimating the influence of species, body size (standardized curved carapace length), sex (male or female) and time in rehabilitation (d) on sea turtle rehabilitation success rates. The dataset contains details of turtles stranded in Florida and taken to rehabilitation between 1986 and $2004(n=374)$. Akaike's information criterion $(A I C)$ indicated that the most parsimonious generalized linear model (GLM) was GLM2. Odds ratios were transformed from the coefficients (log-odds) calculated by GLM2.

\begin{tabular}{|c|c|c|c|c|c|c|c|}
\hline Model & $\begin{array}{l}\text { Explanatory } \\
\text { variables }\end{array}$ & $\begin{array}{l}\text { Coefficients } \\
\text { (odds ratio) }\end{array}$ & df & Deviance & AIC & $x^{2}$ & p-value \\
\hline \multicolumn{8}{|l|}{ GLM1 } \\
\hline \multirow[t]{4}{*}{$A I C=141.5$} & Species & & 2 & 167.7 & 175.7 & 38.188 & $<0.001$ \\
\hline & Sex & & 1 & 129.51 & 139.51 & 0 & 0.987 \\
\hline & Time & & 1 & 156.08 & 166.08 & 26.573 & $<0.001$ \\
\hline & Standardized size & & 1 & 189.75 & 199.75 & 60.243 & $<0.001$ \\
\hline \multicolumn{8}{|l|}{ GLM2 } \\
\hline \multirow[t]{8}{*}{$A I C=141.9$} & Kemp's ridley & 1.756 & 2 & 168.68 & 174.68 & 39.174 & $<0.001$ \\
\hline & & -5.791 & & & & & \\
\hline & Loggerhead & 3.811 & & & & & \\
\hline & & -45.189 & & & & & \\
\hline & Time & 0.005 & 1 & 156.14 & 164.14 & 26.629 & $<0.001$ \\
\hline & & -1.005 & & & & & \\
\hline & Standardized size & 2.244 & 1 & 191.06 & 199.06 & 61.5 & $<0.001$ \\
\hline & & -9.435 & & & & & \\
\hline
\end{tabular}

Table 4. Candidate generalized linear models (GLMs) used to assess the influence of species, body size (standardized curved carapace length), sex (male or female) and time in rehabilitation $(d)$ on sea turtle rehabilitation success rates. The dataset contained details of turtles stranded in Florida and taken to rehabilitation between 1986 and $2004(n=374)$. Models with a difference in Akaike's information criterion (with correction for finite sample sizes; $\triangle \mathrm{AICc}$ ) greater than two were not well supported.

\begin{tabular}{|c|c|c|c|c|c|c|c|c|}
\hline GLM & Intercept & Sex & Species & \begin{tabular}{|c|} 
Time \\
(coefficients)
\end{tabular} & $\begin{array}{c}\text { Standardized size } \\
\text { (coefficients) }\end{array}$ & df & $\mathrm{AICc}$ & $\triangle \mathrm{AICc}$ \\
\hline 1 (Global) & -6.983 & + & + & 0.005 & 2.245 & 6 & 141.7 & 2 \\
\hline 2 & -6.985 & & + & 0.005 & 2.244 & 5 & 139.7 & 0 \\
\hline 3 & -5.135 & & + & & 1.89 & 4 & 164.2 & 25 \\
\hline 4 & -5.160 & + & + & & 1.876 & 5 & 166.2 & 26 \\
\hline 5 & -3.385 & & & 0.003 & 1.569 & 3 & 174.7 & 35 \\
\hline 6 & -3.558 & + & & 0.003 & 1.543 & 4 & 175.8 & 36 \\
\hline 7 & -2.962 & & & & 1.492 & 2 & 190.2 & 51 \\
\hline 8 & -3.160 & + & & & 1.461 & 3 & 190.8 & 51 \\
\hline 9 & -4.261 & & + & 0.004 & & 4 & 199.2 & 60 \\
\hline 10 & -4.411 & + & + & 0.004 & & 5 & 199.9 & 60 \\
\hline 11 & -2.847 & + & & 0.003 & & 3 & 221 & 81 \\
\hline 12 & -3.632 & + & + & & & 4 & 221.5 & 82 \\
\hline 13 & -3.390 & & + & & & 3 & 222.2 & 83 \\
\hline 14 & -2.543 & & & 0.003 & & 2 & 222.4 & 83 \\
\hline 15 & -2.589 & + & & & & 2 & 236.4 & 97 \\
\hline 16 & -2.240 & & & & & 1 & 239 & 99.29 \\
\hline
\end{tabular}


Body size $\left(\mathrm{X}^{2}=61.5, \mathrm{df}=1, \mathrm{p}<\right.$ $0.001)$, time in rehabilitation $\left(X^{2}=26.629\right.$, $\mathrm{df}=1, \mathrm{p}<0.001)$ and species identity $\left(\mathrm{X}^{2}\right.$ $=39.174, \mathrm{df}=2, \mathrm{p}<0.001)$ significantly influenced rehabilitation success. All coefficients were positive, indicating positive influences of these variables on rehabilitation success (GLM2; Tables 3 and 5). Larger turtles of every species were more likely to survive than smaller ones. For every increase in the CCL equivalent to $1 \mathrm{SD}$ from the mean, the odds of survival increase by 9.4 times (Figure 2). Additionally, the longer a turtle spent in rehabilitation, the more likely it was to be released (Figure 3), with the odds of survival increasing by a factor of one for each additional day spent in rehabilitation. The significant species effect in our model revealed that loggerhead turtles were more likely than the other two species to survive rehabilitation, with green turtles the least likely and Kemp's ridleys intermediate (Figures 2 and 3).

The power of our model could be improved if the stranding dataset had more complete records, which greatly limited sample sizes in our full analysis. Only $15.9 \%(n=391)$ of the 2462 records had complete information (Table 2). Sex was the most common variable missing, known for only 503 (29.6\%) turtles with known rehabilitation outcomes (Table 2). Complete details were recorded for only eight percent of hawksbill turtles (Table 2), and the low sample sizes for other species reflect their relative live stranding rates (e.g., leatherback and olive ridley turtles were generally found dead rather than alive).

\section{DISCUSSION}

Any study on the success of rehabilitation efforts should be placed in context; we have summarized findings from a study spanning all stranded turtles documented in Florida over a period of 2 decades. We found that $63 \%$ of sea turtles admitted into rehabilitation facilities were never released back into the wild, and those animals that were released (37\%) often required extended periods in rehabilitation-ranging from months to over three years. Most mortality occurred

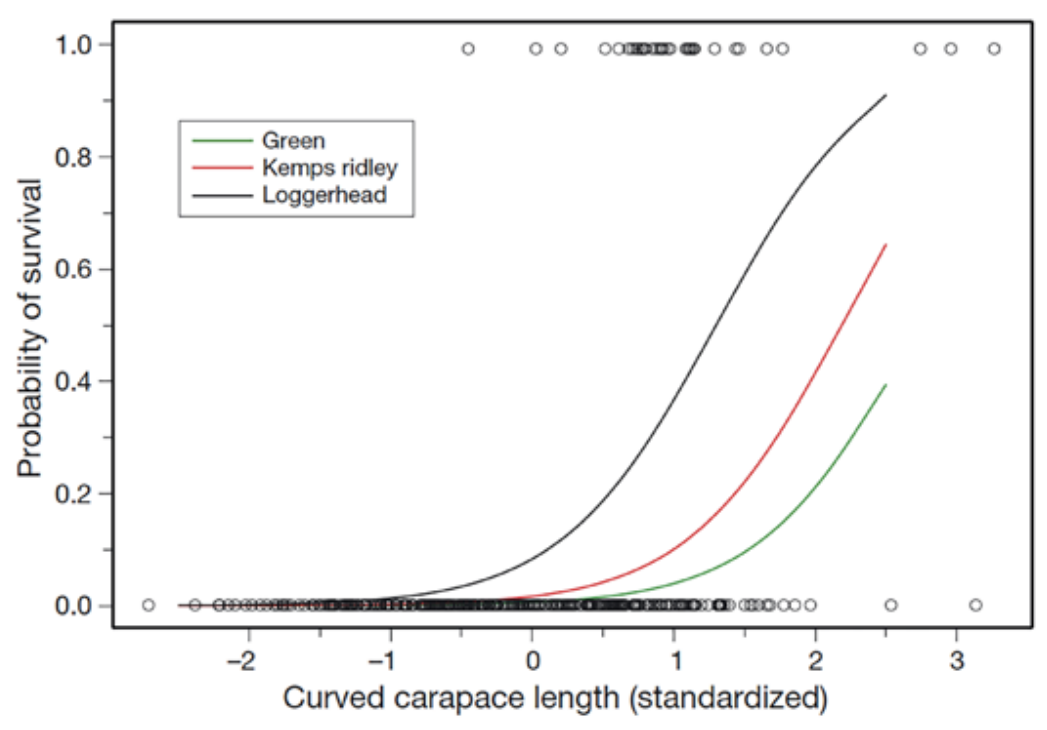

Figure 2. Size (standardized curved carapace length, CCL) versus probability of survival for sea turtles taken for rehabilitation in Florida between 1986 and $2004(n=374)$. A standardized CCL value of 0 represents a turtle of average size (i.e., a Z-score represents the standardized deviation from a mean of zero), negative values indicate smaller turtles, and positive values indicate larger turtles. Solid line: fitted values obtained by the binomial generalized linear model (GLM) for each species; open circles: observed values for all species. As the size of a turtle increases, so does the probability of survival.

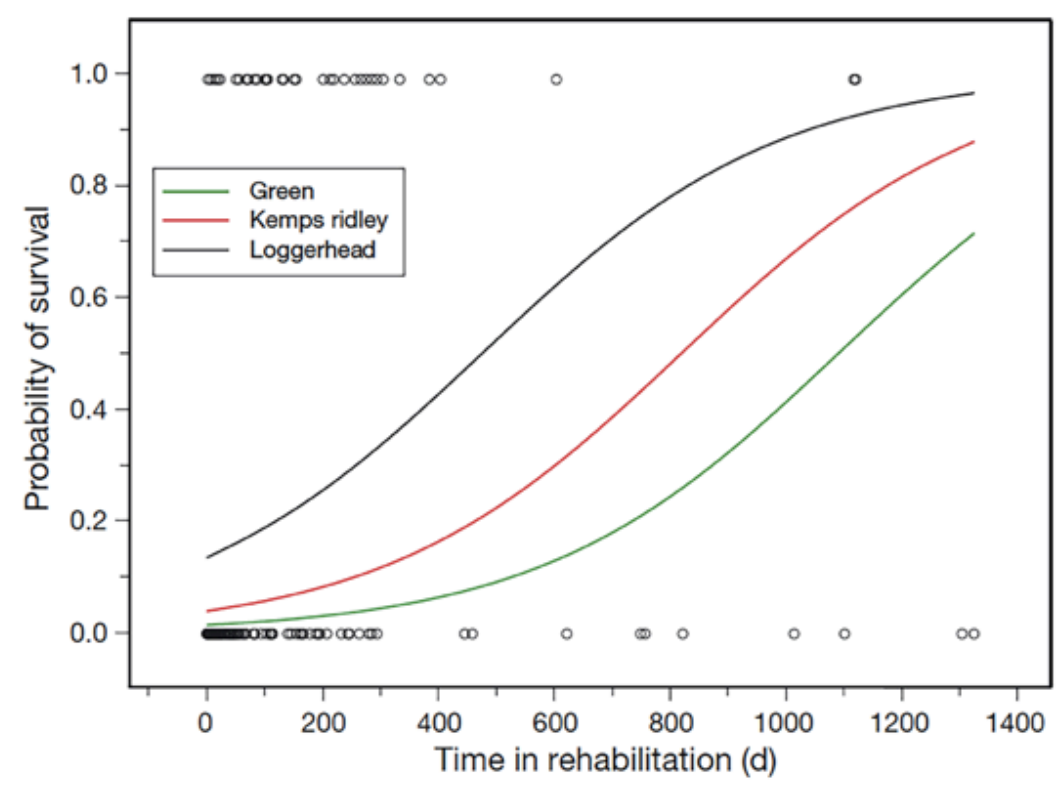

Figure 3. Days spent in rehabilitation versus probability of survival for sea turtles taken for rehabilitation in Florida between 1986 and $2004(n=$ 374). Solid line: fitted values obtained by the binomial generalized linear model (GLM) for each species; open circles: observed values for all species. As the number of days a turtle spends in rehabilitation increases, so does the probability of survival. 
Table 5. Attributes of sea turtles admitted into rehabilitation centres in Florida between 1986 and 2004 ( $n=374$ ), including body size and sex ratios of 4 species and the duration that each spent in rehabilitation prior to successful release back into the wild.

\begin{tabular}{|c|c|c|c|c|c|}
\hline \multirow[t]{2}{*}{ Species } & \multirow{2}{*}{$\begin{array}{c}\text { Body size }(\mathrm{cm}) \\
\text { Mean (SD, range) }\end{array}$} & \multirow{2}{*}{$\begin{array}{c}\text { Time }(\mathrm{d}) \\
\text { Mean (SD, range) }\end{array}$} & \multicolumn{3}{|c|}{$\operatorname{Sex}(n)$} \\
\hline & & & Female & Male & Unknown \\
\hline \multirow{2}{*}{ Green } & 44 & 72.4 & \multirow{2}{*}{122} & \multirow{2}{*}{62} & \multirow{2}{*}{184} \\
\hline & $(14.12,23.5-108.1)$ & $(206.91,0-1323)$ & & & \\
\hline \multirow{2}{*}{ Hawksbill } & 44.9 & 15 & \multirow{2}{*}{6} & \multirow{2}{*}{3} & \multirow{2}{*}{9} \\
\hline & $(19.11,24.1-76.6)$ & $(23.0,0-60)$ & & & \\
\hline \multirow{2}{*}{ Kemps ridley } & 40.2 & 54.5 & 14 & 6 & 20 \\
\hline & $(14.79,16.5-71.9)$ & $(77.22,0-294)$ & & & \\
\hline \multirow{2}{*}{ Loggerhead } & 84.7 & 84.7 & 93 & 77 & 70 \\
\hline & $(16.18,48.7-119)$ & $(151.75,0-1119)$ & & & \\
\hline
\end{tabular}

early in the rehabilitation process (within a few weeks), but many animals died even after substantial periods in care (e.g., over three years). We found strong differences among species in terms of rehabilitation success; loggerhead turtles were most likely to survive rehabilitation, followed by Kemp's ridleys and green turtles, and larger individuals of all species were more likely to survive than smaller individuals. Underlying these patterns, however, is unexplained variance that includes the causes of mortality and severity of injuries, the treatments provided to individual turtles, and the likelihood of sick or injured turtles becoming stranded and found. Therefore, the results of our study do not necessarily apply to other contexts in which different parameters may be known about injured turtles. Low success rates are typical of many rehabilitation programs (Tribe and Brown 2000), but our findings indicate that Florida sea turtle rehabilitation success rates are higher than those in Australia (26\%; Table 1).

Euthanasia is an option for some stranded turtles whose injuries are severe enough to indicate that rehabilitation may be unsuccessful (Karesh 1995; Tribe and Brown 2000; Moore et al 2007). For turtles that appear capable of making a full recovery, however, the longer they survive in captivity the more likely they are to be released back into the wild (Figure 1). This pattern emerges because those individuals that have the most severe injuries die very quickly in the rehabilitation process and as individuals are successfully nursed through the first several weeks of rehabilitation (when the health complications are most severe) their odds of surviving dramatically increases (Figure 1). Individuals that require long periods in rehabilitation, however, could present potential risks to wild sea turtle populations. During rehabilitation, animals may be exposed to pathogens to which they do not have immunity (Tribe and Brown 2000; Moore et al 2007). These individuals may transmit diseases, which have been acquired or modified in rehabilitation, to the wild population upon release (Tribe and Brown 2000; Moore et al 2007).

Although many individual turtles are successfully released following extended rehabilitation, we know very little about whether these animals ultimately survive. In general, reptile repatriation projects are not very successful, and thus long-term monitoring of sea turtle survival after release from rehabilitation is important (Dodd and Seigel 1991; Karesh 1995; Tribe and Brown 2000). Such studies are scarce because of the expense associated with monitoring rehabilitated individuals in the open ocean after release (Cardona et al 2012; Mestre et al 2014). Satellite tracking of rehabilitated loggerhead turtles has revealed that their movement behavior is more variable than wild turtles; released turtles travel at higher speeds, turn back more often, spend more time on the continental shelf and at the surface during the night compared to healthy turtles (Cardona et al 2012). Although this suggests that rehabilitated loggerhead turtles can survive for at least several months after release back into the wild, the behavioral anomalies they have exhibited casts uncertainty upon whether these individuals will survive and reproduce, and thus contribute to the population over the longer term (Cardona et al 2012). Another study on loggerhead and green turtles suggested that rehabilitation is promising, since turtles migrated towards known foraging areas following release (Mestre et al 2014).

Understanding the capacity for released turtles to breed and thus contribute directly to population recruitment is also limited (Karesh 1995; Cardona et al 2012; Mestre et al 2014). The majority of 
information about rehabilitated sea turtles has been gleaned from animals that have been incidentally hooked or netted by fishing gear and released immediately after hook removal or untangling from netting aboard the fishing vessel. The survival outcome for these animals may differ from individuals that require long and complicated rehabilitation in captivity for more serious illness or injury (Cardona et al 2012). Thus, further investigation into post-release survival rates of rehabilitated sea turtles is necessary to better assess rehabilitation success and its effects on behavior (Cardona et al 2012; Mestre et al 2014).

The conservation value of animals during rehabilitation, and those that remain in captivity indefinitely due to the serious nature of their injuries may be especially important as a mechanism to educate the public about wildlife conservation (Feck and Hamann 2013). In our study, $1.6 \%$ of surviving sea turtles remained in captive facilities such as aquariums and public education centres. Rehabilitation facilities play a major role in providing environmental education and raising public awareness about conservation issues (Tribe and Brown 2000; Moore et al 2007; Cardona et al 2012; Feck and Hamann 2013). For example, a live turtle in rehabilitation can facilitate effective outreach programs about habitat conservation (Moore et al 2007; Feck and Hamann 2013). Allowing people to interact directly with injured animals develops a sense of stewardship for wildlife which may foster community involvement in local habitat protection and conservation (Tribe and Brown 2000; Feck and Hamann 2013). Additionally, the release of rehabilitated turtles can have important public educational benefits (Tribe and Brown 2000; Cardona et al 2012; Mestre et al 2014) because such opportunities are often advertised widely as media events to raise awareness of the threats facing wildlife. Although this may not contribute to conservation directly (in terms of population growth), continuing to rehabilitate these animals in facilities that are open to the public likely contributes to conservation in other ways, by facilitating a widespread understanding of the causes and nature of wildlife injuries. The public can also use this knowledge to place political pressure on decisionmakers in a context where conservation measures are known, feasible and available, but not implemented because of lack of will by those responsible.

Our results provide decision-makers with a greater understanding of the relatively low success rates of sea turtle rehabilitation and the phenotypic attributes that influence rehabilitation success, enabling prioritization of animals when the number of turtles exceeds resource availability. When resources are limited, we recommend focusing efforts on larger adult turtles, which are more likely to survive rehabilitation. When possible, priority care should be provided to species that are easier to successfully rehabilitate (e.g., loggerhead turtles in Florida) or rare species for the area. Key future studies should include more thorough collection of data on stranded and rehabilitated animals and post-release monitoring of released individuals to determine survival rates and reproductive potential. This information can then be used to model the potential conservation outcomes of rehabilitation efforts on population dynamics. Overall, decision-makers should continue to promote legislative protection efforts that seek to reduce strandings, provide funding support for facilities that rehabilitate threatened animals, and provide funding for research that investigates the causes and consequences of strandings.

\section{ACKNOWLEDGEMENTS}

We are grateful to the Florida Marine Research Institute and Florida Sea Turtle Stranding and Salvage Network for making data accessible. We thank A. Foley, director of STSSN, for permission to use the dataset for our research, and R. Jones and S. Blomberg for statistical advice.

\section{LITERATURE CITED}

Agresti, A., and B. A. Coull. 1998. Approximate is Better than 'Exact' for Interval Estimation of Binomial Proportions. American Statistician 52: 119-126.

Allen, L. K. 2000. Protected Species and New England Fisheries: An Overview of the Problem and Conservation Strategies. Northeastern Naturalist 7: 411-418.

Bagarinao, T. U. 2011. The Sea Turtles Captured by Coastal Fisheries in the Northeastern Sulu Sea, Philippines: Documentation, Care and Release. Herpetological Conservation and Biology 6: 353-363.

Barto, K. 2012. MuMIn Multi-model Inference Package, version 1.8.4. Available from: <https:// cran.r-project.org/web/packages/_MuMIn/index. html>.

Biddle, T. M., and C. J. Limpus. 2011. Marine Wildlife Stranding and Mortality Database Annual Reports 2005-2010. Marine Turtles. Conservation and Technical Data Report, Department of Environment and Resource Management, Brisbane, Australia. 
Burnham, K. P., and D. R. Anderson. 1998. Model Selection and Inference: A Practical InformationTheoretic Approach. Springer-Verlag: New York, NY.

Cardona, L., G. Fernández, M. Revelles, and A. Aguilar. 2012. Readaptation to the Wild of Rehabilitated Loggerhead Sea Turtles (Caretta caretta) Assessed by Satellite Telemetry. Aquatic Conservation 22: 104-112.

Casal, A. B., and J. Orós. 2009. Plasma Biochemistry and Haematology Values in Juvenile Loggerhead Sea Turtles Undergoing Rehabilitation. Vet Record 164: 663-665.

Dodd, C. K., and R. A. Seigel. 1991. Relocation, Repatriation, and Translocation of Amphibians and Reptiles: Are They Conservation Strategies that Work? Herpetologica 47: 336-350.

Dutton, P. H., and D. Squires. 2008. Reconciling Biodiversity with Fishing: A Holistic Strategy for Pacific Sea Turtle Recovery. Ocean Development and International Law 39: 200-222.

Feck, A. D., and M. Hamann. 2013. Effect of Sea Turtle Rehabilitation Centres in Queensland, Australia on People's Perceptions of Conservation. Endangered Species Research 20: 153-165.

Ferraro, P. J., and S. K. Pattanayak. 2006. Money for Nothing? A Call for Empirical Evaluation of Biodiversity Conservation Investments. PLoS Biology 4: e105.

Foley, A. M., B. A. Schroeder, A. E. Redlow, K. J. Fick-Child, and W. G. Teas. 2005. Fibropapillomatosis in Stranded Green Turtles (Chelonia mydas) from the Eastern United States (1980-98): Trends and Associations with Environmental Factors. Journal of Wildlife Diseases 41: 29-41.

Goldberg, D.W., J. Wanderlinde, I. M. A. Freire, L. C. P. da Silva, and N. R. P. Almosny. 2011. Serum Biochemistry Profile Determination for Wild Loggerhead Sea Turtles Nesting in Campos dos Goytacazes, Rio de Janeiro, Brazil. Ciências Rurais 41: 143-148.

Greenland, J. A., and C. J. Limpus. 2006. Marine Wildlife Stranding and Mortality Database Annual Report 2004. III. Marine Turtles. Conservation Technical and Data Report. Environmental Protection Agency: Brisbane, Australia.
Greenland, J. A., and C. J. Limpus. 2008. Marine Wildlife Stranding and Mortality Database Annual Report 2003. III. Marine Turtles. Conservation Technical and Data Report. Environmental Protection Agency: Brisbane, Australia.

Greenland, J. A., C. J. Limpus, and K. J. Currie. 2004. Queensland Marine Wildlife Stranding and Mortality Database Annual Report 2001-2002. III. Marine Turtles. Conservation Technical and Data Report. Environmental Protection Agency: Brisbane, Australia.

Haines, J. A., and C. J. Limpus. 2001. Marine Wildlife Stranding and Mortality Database Annual Report, 2000. III. Marine Turtles. Conservation Technical and Data Report. Queensland Parks and Wildlife Service: Brisbane, Australia.

Haines, J.A., C. J. Limpus, and S. Flakus. 2000. Marine Wildlife Stranding and Mortality Database Annual Report, 1999. III. Marine Turtles. Conservation Technical and Data Report. Queensland Parks and Wildlife Service: Brisbane, Australia.

IUCN-International Union for Conservation of Nature.1995. A Global Strategy for the Conservation of Marine Turtles. IUCN Species Survival Commission Marine Turtle Specialist Group, Cambridge.

Karesh, W. B. 1995. Wildlife Rehabilitation: Additional Considerations for Developing Countries. Journal of Zoo and Wildlife Medicine 26: 2-9.

Mestre, F., M. P. Braganca, A. Nunes, and M. E. dos Santos. 2014. Satellite Tracking of Sea Turtles Released After Prolonged Captivity Periods. Marine Biology Research 10: 996-1006.

Moore, M., G. Early, K. Touhey, S. Barco, F. Gulland, and R. Wells. 2007. Rehabilitation and Release of Marine Mammals in the United States: Risks and Benefits. Marine Mammal Science 23: 731-750.

R Development Core Team. 2012. R: A Language and Environment for Statistical Computing. R Foundation for Statistical Computing, Vienna.

Shaver, D. J., and W. G. Teas. 1999. Stranding and Salvage Networks. Pp. 152-155n in Research and Management Techniques for the Conservation of Sea Turtles (K. L. Eckert, K. A. Bjorndal, F.A. AbreuGrobois, and M. Donnelly, editors). Publ. No. 4, IUCN/ SSC Marine Turtle Specialist Group, Washington, DC. 
Teas, W. G. 1993. Species Composition and Size Class Distribution of Marine Turtle Strandings on the Gulf of Mexico and Southeast United States Coasts, 1985-1991. NOAA Tech Memo NMFSSEFSC-409, Miami, FL.

Tribe. A., and P. R. Brown. 2000. The Role of

Wildlife Rescue Groups in the Care and

Rehabilitation of Australian Fauna. Human

Dimensions of Wildlife 5: 69-85.

Wallace, B. P., A. D. DiMatteo, A. B. Bolten, and M. Y. Chaloupka. 2011. Global Conservation Priorities for Marine Turtles. PLoS ONE 6: e24510.

Wimberger, K., C. T. Downs, and R. S. Boyes. 2010. A Survey of Wildlife Rehabilitation in South Africa: Is There a Need for Improved Management? Animal Welfare 19:481-499.
(C) The authors 2015. Reprinted under Open Access under Creative Commons by Attribution License. Use, distribution and reproduction are unrestricted.

Baker, L., W. Edwards, and D. A Pike. Endangered Species Research Vol. 29: 13-21, 2015. doi: 10.3354/esr00696

Submitted: August 18, 2014; Accepted: August 15, 2015. Proofs received from author(s): October 12 , 2015.

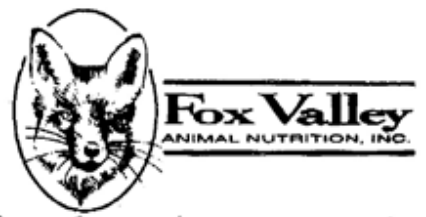

Day One formulas are species-specific formulations having the required protein and fat for neonatal growth. Recommended for those neonates who are orphaned, or will not, or cannot suckle on their own.

* All-milk protein from premium food-grade milk ingredients

* Complete complement of vitamins and minerals

* Balanced fatty acids including medium chain fatty acids for easy digestion

We specialize in serving the wildlife, domestic, and exotic-animal rehabilitator. For information on our "Sponsorship of Goods" program, (a donation of products from you to your local center, group, or wildlife organization on your behalf),

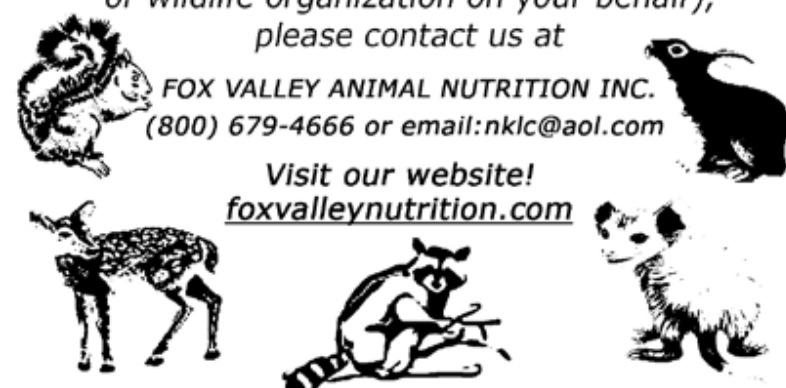

